\title{
Resistance to Reform: Status Quo Bias in the Presence of Individual-Specific Uncertainty
}

\section{Citation}

Fernandez, Raquel, and Dani Rodrik. 1991. "Resistance to Reform: Status Quo Bias in the Presence of Individual-Specific Uncertainty." American Economic Review 81, no. 5: 1146-1155.

\section{Permanent link}

http://nrs.harvard.edu/urn-3:HUL.InstRepos:37927057

\section{Terms of Use}

This article was downloaded from Harvard University's DASH repository, and is made available under the terms and conditions applicable to Other Posted Material, as set forth at http:// nrs.harvard.edu/urn-3:HUL.InstRepos:dash.current.terms-of-use\#LAA

\section{Share Your Story}

The Harvard community has made this article openly available.

Please share how this access benefits you. Submit a story.

\section{Accessibility}




\title{
Resistance to Reform: Status Quo Bias in the Presence of Individual-Specific Uncertainty
}

\author{
By Raquel Fernandez and Dani Rodrik*
}

\begin{abstract}
Why do governments so often fail to adopt policies which economists consider to be efficiency-enhancing? Our answer to this question relies on uncertainty regarding the distribution of gains and losses from reform. We show that there is a bias towards the status quo (and hence against efficiency-enhancing reforms) whenever some of the individual gainers and losers from reform cannot be identified beforehand. There are reforms which, once adopted, will receive adequate political support but would have failed to carry the day ex ante. The argument does not rely on risk aversion, irrationality, or hysteresis due to sunk costs. (JEL D72, F13)
\end{abstract}

Why do governments so often fail to adopt policies that economists consider to be efficiency-enhancing? This is one of the fundamental questions of political economy. The answer usually relies on what may be called a "nonneutrality" in the way that the gains and losses from the reform are distributed within society: the gainers from the status quo are taken to be politically "strong" and the losers to be politically "weak," thereby preventing the adoption of reform. (Nondistorting transfers would of course short-circuit this problem, but they are usually ruled out as unavailable.) In pressure-group models, this nonneutrality

\footnotetext{
* Fernandez: Department of Economics, Boston University, 270 Bay State Rd., Boston, MA 02215, and NBER; Rodrik: Harvard University, CEPR, and NBER. Raquel Fernandez's work was supported by NSF grant SES 89-08390 and by a Hoover Fellowship. Dani Rodrik's work was supported by the World Bank through a research project on Sustainability of Trade Reform (RPO 675-32) and by an NBER Olin Fellowship. We thank Loreto Lira for research assistance, the Japanese Corporate Associates Program of the Kennedy School for financial support, and Alberto Alesina, Guillermo Calvo, Avinash Dixit, Konstantine Gatsios, Larry Karp, Anne Krueger, Timur Kuran, Marc Lindenberg, Mike Mussa, three referees, and participants at the NBER Conference on Political Economics and at seminars at Boston University, Chicago Business School, Dartmouth College, The Federal Reserve Board, Harvard University, The International Monetary Fund, NBER Summer Institute, and Syracuse University for useful comments.
}

typically expresses itself in the form of differential organizational ability: for example, the gains from the status quo may be concentrated on a small number of individuals while the losses are diffuse, such that free riding hampers the lobbying efforts of the second group to a much greater extent. ${ }^{1}$ In voting models, the nonneutrality operates through distributional consequences across individuals, so that the median voter may prefer the status quo to a reform that would increase aggregate real income. ${ }^{2}$

We propose a different source of nonneutrality in this paper, one that relies on uncertainty regarding the distribution of gains and losses from reform. What we will show, specifically, is that there is a bias toward the status quo (and hence against efficiencyenhancing reforms) whenever (some of) the individual gainers and losers from reform cannot be identified beforehand. ${ }^{3}$ There are

\footnotetext{
${ }^{1}$ See Rodrik (1986) for another example.

${ }^{2}$ We thank Jagdish Bhagwati for suggesting the formulation of our problem in terms of a "nonneutrality."

${ }^{3}$ Anne O. Krueger (1989) coins the phrase "identity bias" to describe a somewhat related problem, one that arises from the possibility that the precise knowledge of the losers' identities evokes a more sympathetic response from the general population toward their plight than if their identities were unknown. This is a psychological Schellingesque distinction between statistical and individual-specific information which differs from ours (see Thomas C. Schelling, 1984 Ch. 5). See also William Samuelson and Richard Zeckhauser (1988)
} 
reforms which, once adopted, will receive adequate political support but would have failed to carry the day ex ante. Significantly, the result holds even if individuals are riskneutral, forward-looking, and rational and in the absence of aggregate uncertainty regarding the consequences of reform. Moreover, the conclusion does not rely on hysteresis due to sunk costs.

While the logic is general, we will use trade liberalization as an example to motivate our approach and the specific model. Trade reform is a particularly interesting example because there is possibly no area in which there is greater consensus among economists. ${ }^{4}$ Despite the well-known gains from trade, however, trade liberalization is politically one of the most contentious actions that a government can take. Historically, significant liberalizations have almost always been associated with changes in political regime or else have been undertaken at a point of economic crisis. There is by now a large literature on the political economy of trade policy. ${ }^{5}$

A striking paradox, particularly in developing countries, is that while trade reform typically turns out to be a boon to large segments of the private sector, these same groups are rarely enthusiastic about reform early on. This is a pattern observed in Taiwan and South Korea (early 1960's), Chile (1970's), and Turkey (1980's), the leading cases of trade liberalization in the developing world. In all three cases, reform was imposed by authoritarian regimes and against the wishes of business, even though

for a broad discussion of the sources of status quo bias at the level of individual decision-making, and Timur Kuran (1988) for a review and critique of the related literature.

${ }^{4}$ Even when the strictly economic case for free trade fails, economists are generally quick to embrace it for the same practical reason that Churchill embraced democracy, namely as the lesser evil among possible alternatives. See, for example, Paul Krugman (1987).

${ }^{5}$ See Robert E. Baldwin (1985 Ch. 1) and Bhagwati (1988) and the references therein. On median-voter models of trade policy, see in particular Wolfgang Mayer (1984) and Mayer and Raymond Riezman (1987). business emerged as the staunchest defender of outward orientation once the policies were in place. ${ }^{6}$ Existing models of trade reform cannot account for such apparently inconsistent behavior. However, the anomaly is consistent with the results of our model. In each of these cases, there existed considerable uncertainty regarding the identity of the eventual beneficiaries (and losers) from the reform. As with any largescale price reform, it was difficult to predict ex ante precisely which sectors and which entrepreneurs would be the winners. In such a setting, the nonneutrality identified in this paper comes into play in full force: when individuals do not know how they will fare under a reform, aggregate support for reform can be lower than what it would have been under complete information, even when individuals are risk-neutral and there is no aggregate uncertainty. Moreover, the role of uncertainty in determining the outcomes is not symmetric, since reforms that are initially rejected will continue to be so in the future while reforms that are initially accepted may find themselves reversed over time.

In Section I, we provide a simple, diagrammatic exposition which shows the logic of the argument in as transparent a manner as possible. In Sections II and III, we develop a model which embeds the results within standard trade theory and demonstrates that the results can obtain within a general-equilibrium framework. We conclude the paper in Section IV.

\section{The Argument}

The maintained assumption in this paper is that a policy reform is more likely to be adopted the larger is the number of individuals in favor of it. For concreteness, it is convenient to use the language of majority voting (although our argument will also hold for some other social-choice mechanisms).

Figure 1A shows schematically an economy in which individuals are aligned uni-

\footnotetext{
${ }^{6}$ For more detail on these cases, see our working paper (Fernandez and Rodrik, 1990).
} 
A.

Mojority is better off with reform ex post:

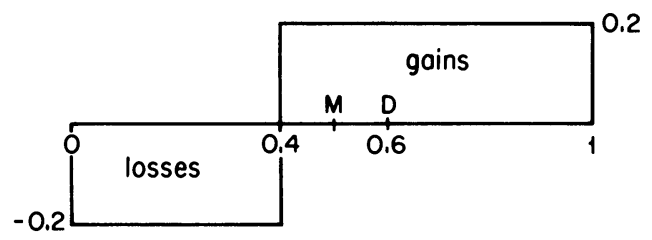

But majority votes against reform ex ante:

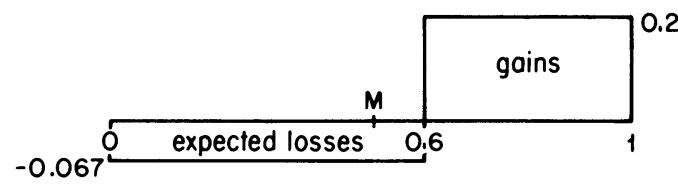

B. Mojority is worse-off with reform ex post:

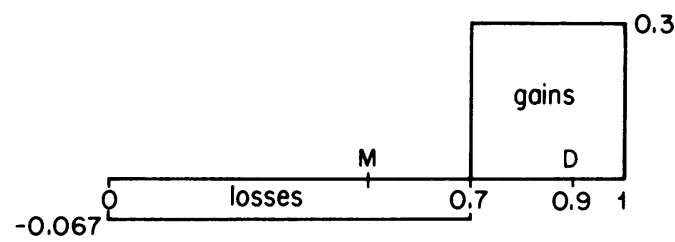

But majority votes for reform ex onte:

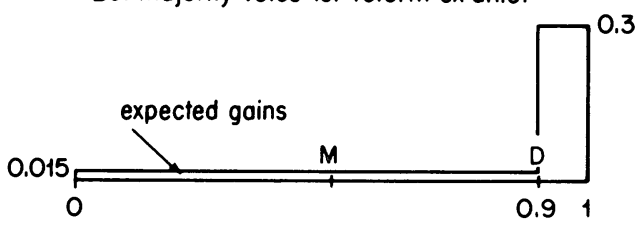

Figure 1. Gains ANd Losses from Reform

formly on a continuum between 0 and 1 , as represented by the horizontal axis. The midpoint of the axis is indicated by " $M$." We assume that the economy has two productive sectors, sectors W (for winners) and $\mathrm{L}$ (for losers). D represents the demarcation point between the status quo allocation of individuals in the two sectors: individuals in sector $\mathrm{L}$ are located to the left of $\mathrm{D}$, and individuals in sector $\mathrm{W}$ are to the right of D. As drawn, a majority of the individuals are in the $\mathrm{L}$ sector prior to reform.

Now consider a reform that, if adopted, would increase the return to $\mathrm{W}$-sector individuals, lower the return to L-sector individuals, and draw individuals from the second sector to the first. The top panel of Figure
1A shows the distributional outcome, with the two boxes representing the gains and losses accruing to individuals on different segments of the continuum. The magnitudes of gains and losses are indicated by the numbers corresponding to each box. All individuals already in the $\mathrm{W}$ sector naturally gain, but there are also some gainers among individuals who were previously employed in the other sector. Since the reform is taken to enhance efficiency, the gainers' box is larger in area than the losers' box (the net gain is 0.04). Notice that, as the figure is drawn, gainers constitute a majority. In the presence of complete certainty, the reform in question would therefore be adopted: the potential winners in the $\mathrm{L}$ sector would join $\mathrm{W}$-sector individuals to pass the reform.

Now suppose that the individuals in the $\mathrm{L}$ sector do not know who among them will be winners and who will be losers and that $e x$ ante they consider it equally likely that any single one of them will be a winner. All that they know is the aggregate number (or the proportion) of winners. Will there still be a majority in favor of reform? Note that uncertainty renders all L-sector individuals identical ex ante. To know which way to vote, they will compute the expected benefit from reform. The expected benefit equals the weighted average of the gains and losses, with the weights equaling the probability of each outcome occurring. The lower panel of Figure $1 \mathrm{~A}$ shows that the expected benefit is negative $(-0.067$ per L-sector individual). Since the L sector represents a majority of the economy at the outset, the proposed reform would not be adopted. The losses to the many are pulling down the gains to the few, leaving an expected loss for all but the individuals already in the $\mathrm{W}$ sector. Note that the reform is not adopted even though (i) individuals are risk-neutral, (ii) a majority would vote for the reform ex post, and (iii) both (i) and (ii) are common knowledge.

This example establishes that the presence of individual-specific uncertainty can distort aggregate preferences. However, it does not establish that there will necessarily be a bias against reform. One can also construct examples in which this type of uncertainty leads to the adoption of a reform that 
turns out to be unpopular ex post. ${ }^{7}$ Figure $1 \mathrm{~B}$ shows such an example. The top panel once again displays the actual outcomes under reform, with only a minority benefiting this time. Under certainty, therefore, this reform would not command majority support. However, when L-sector individuals are all equally uncertain about how they will fare under reform, the outcome could be different. When there is uncertainty, the expected benefit could be positive for all. This is shown in the lower panel of Figure 1B. The expected gain per L-sector individual can be calculated to be 0.015 in this case: $[(0.3 \times 0.2)+(-0.067 \times 0.7)] \times(0.9)^{-1}$.

There is an important asymmetry between the two cases, however. In the second case (in which a reform is passed and turns out to be unpopular), information is revealed as to how individuals actually fare under the reform. Therefore, if there is ever a second vote or a chance to reconsider, the reform may be repealed. In the other case (in which reform is not passed), no new information is revealed, since the status quo is maintained. This asymmetry between the two cases leads to a status quo bias.

This may appear to be a contrived example with many loose threads. For example, what keeps returns in the two sectors from being equalized in equilibrium, and is that necessary to the argument? What is the source of uncertainty regarding the identities of gainers and losers? As we will show in the next section, it is possible to generalize the example and to place it in the context of a simple general-equilibrium model.

\section{The Model}

Consider a two-sector perfectly competitive economy in which each sector produces a distinct good, $X$ or $Y$, using one factor of production, labor $(L)$, and with constantreturns-to-scale technology. There is no harm in thinking of $X$ and $Y$ as aggregates

\footnotetext{
${ }^{7}$ Bhagwati (1981), for example, argues that elites in developing countries may sometimes support policy reforms which end up hurting them due to the policymaker's occasional inability to establish the distributional impact of a reform.
}

made up of individual commodities. Workers (or individuals) in each sector can by the same logic be interpreted as producing different products. Thus,

$$
\begin{aligned}
& X=L_{x} / a_{x} \\
& Y=L_{y} / a_{y}
\end{aligned}
$$

and

$$
L_{x}+L_{y}=\bar{L}
$$

where $a_{j}>0, j=x, y$.

Labor cannot relocate between sectors costlessly. The cost to an individual's relocation is modeled as having two components: $\theta$, a known general investment cost incurred prior to switching sectors, and $c_{i}$, an individual-specific cost element incurred only upon actually switching sectors. The value of the second component, however, is unknown to the individual and is revealed only if the general investment cost is incurred. Only the distribution of $c_{i}, f(c)$, is known. ${ }^{8}$ The interpretation behind this formulation is that workers have different abilities and productivities and, therefore, that their "net" wages in another sector will differ. Workers cannot know what their true abilities are before sinking the cost $\theta$, which can also be thought of as investment in sectorspecific human capital. ${ }^{9}$ Alternatively, entrepreneurs may not have the information necessary to be able to determine precisely what their firm's cost structure would be in the new industry. Only after obtaining this information at cost $\theta$ is their cost structure revealed. This is a plausible way of capturing the uncertainty that is likely to surround each individual's prospects under reform.

Workers must therefore make two decisions: (i) whether to undertake the general investment cost and, if the first is decided

\footnotetext{
${ }^{8}$ For simplicity of exposition, we are assuming that the relocation cost is independent of the sector from which the individual is relocating.

${ }^{9}$ However, individuals who desire to switch sectors are not free to do so without incurring both costs (i.e. were they to do so, it is assumed that their marginal product would be zero).
} 
affirmatively, then (ii) whether to switch sectors and thereby incur the cost $c_{i}$. To find the optimal choice, we start with the second decision. A worker who has invested $\theta$ will choose to switch from industry $y$ to industry $x$ if the difference between wages in the two industries is larger than her $c_{i}$. Thus, for any wage difference, there exists a level of $c$, $\tilde{c}$, such that all workers with $c_{i} \leq \tilde{c}$ will switch to industry $x$. Therefore, let

$$
\tilde{c}=\tilde{w}_{x}-\tilde{w}_{y}
$$

where $\tilde{w}_{j}$ is the equilibrium wage in sector $j$ that results from the reform.

Ex ante, workers are identical and atomistic. Consequently, a worker in sector $Y$ will decide to incur the general investment cost if her expected net benefit from doing so is nonnegative, that is, if

$$
\begin{gathered}
F(\tilde{c})\left[\tilde{w}_{x}-\int_{\underline{c}}^{\tilde{c}} f(c) c d c[F(\tilde{c})]^{-1}\right] \\
+[1-F(\tilde{c})] \tilde{w}_{y}-\theta \geq \tilde{w}_{y}
\end{gathered}
$$

where $c \geq 0$ is the infimum over the values taken by $c_{i}$ and $F(c)$ is the cumulative distribution function. The left-hand side represents expected income when $\theta$ is incurred, while the right-hand side is the (certain) level of income in the absence of the investment. Rearranging terms, we obtain

$$
\left[\tilde{w}_{x}-\tilde{w}_{y}\right] F(\tilde{c})-\int_{\underline{c}}^{\tilde{c}} f(c) c d c-\theta \geq 0 .
$$

In order to illustrate our argument most clearly, we consider a country that is small in world markets, so relative prices within each aggregate are fixed by world price ratios. Let this country initially have a tariff of a magnitude such that

$$
P^{0}=a_{x} / a_{y}
$$

where $P=p_{x} / p_{y}$ is the (tariff-inclusive) relative price of good $X$ in terms of good $Y$. We normalize the domestic price of the imported good, good $Y$, to equal 1 . Thus, decreases in the value of the tariff have the effect of increasing the relative price of good
$X$. Labor's initial distribution between sectors, $L_{y}^{0}$ and $L_{x}^{0}$, is given by history. Perfect competition in the labor market ensures that

$$
w_{j}=p_{j} / a_{j} \quad j=x, y .
$$

Therefore, given the initial tariff level, $w_{x}^{0}=$ $w_{y}^{0}$. Note that $w_{y}$ is invariant with respect to $P$ and equal to $1 / a_{y}$.

Let us analyze the behavior of this economy with respect to changes in the tariff rate commencing at $P^{0}$. As the tariff rate falls, $\tilde{w}_{x}-\tilde{w}_{y}$ increases, but initially no individual will choose to undertake the general investment cost. Simultaneously, the value of $\tilde{c}$ increases, as $d \tilde{c} / d P=d \tilde{w}_{x} / d P=$ $1 / a_{x}$. Note that the left-hand side (LHS) of (3) is increasing with $P$ (i.e., $d$ (LHS) $/ d P=$ $\left.F(\tilde{c}) / a_{x}>0\right)$. Therefore, at a sufficiently high relative price, $P^{*}$, all $y$-sector individuals are indifferent between incurring the investment cost and not. Those individuals who choose to undertake the general investment cost and have a $c_{i} \leq c^{*}$ will move to sector $x$ (where $c^{*}$ is the $\tilde{c}$ associated with $\left.P^{*}\right) .{ }^{10}$ Any further increases in the relative price have all $y$-sector individuals strictly preferring to incur the general investment cost and, as $\tilde{c}$ and the relative wage of sector $x$ increase monotonically with $P$, further labor reallocation (see Fig. 2).

We wish to show that there exist circumstances in which trade reform (in the manner of a tariff decrease) would be voted in under complete certainty as to the ex post identity of individuals but would be rejected under uncertainty, despite the fact that individuals are risk-neutral. Consider, therefore, an initiative to change prices in this economy from $P^{0}$ to $P^{*}$ by reducing the tariff level accordingly. Since $P^{*}$ is the price ratio at which all individuals are exactly indifferent between undertaking the invest-

\footnotetext{
${ }^{10}$ This zero-one behavior with respect to undertaking the general investment cost is a product of the linearity of technology. A decreasing marginal product of labor, as in the Ricardo-Viner model, would exhibit a continuously increasing proportion of individuals willing to incur the general investment cost as a function of relative prices.
} 


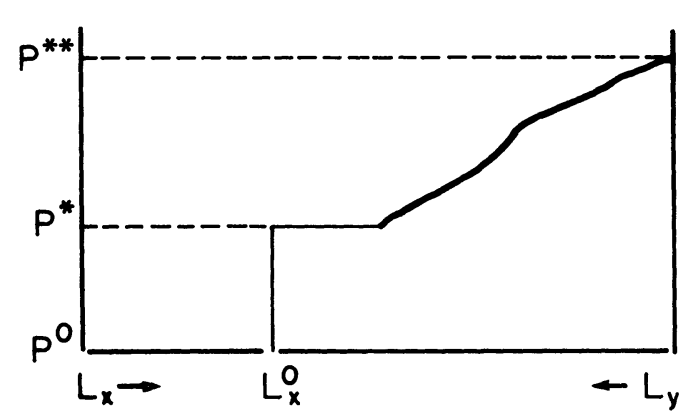

Figure 2. Allocation of Labor Between Sectors as a Function of Relative Prices

ment cost and not, $c^{*}$ is exactly that level of $\tilde{c}$ such that

$$
\tilde{c} F(\tilde{c})-\int_{\underline{c}}^{\tilde{c}} f(c) c d c-\theta=0 .
$$

If asked to vote on whether to undertake this reform, all individuals in sector $y$ would vote against this proposal. To see this, note that the purchasing power of the wage earned by an individual who remains in sector $y$ is unchanged in terms of good $Y$ and is strictly lower in terms of good $X$. Given that at $P^{*} y$-sector individuals are indifferent between undertaking the investment cost (under the assumption that the reform will go through) and not investing and remaining in sector $y$ under the new price system, these individuals' expected real income from the reform must be lower than that resulting from remaining with the status quo. Therefore, if $L_{y}^{0} \geq L_{x}^{0}$, this measure would be rejected by majority vote.

If, on the other hand, individuals knew ex ante what their identities would be under the new regime (i.e., if each individual knew her $c_{i}$ ) and were then asked if they would be willing to pay $\theta+c_{i}$ in order to switch sectors, there may now be some $y$-sector individuals who would be willing to do so and, accordingly, willing to vote in favor of the reform. ${ }^{11}$ That is, it is easy to show that,

\footnotetext{
${ }^{11}$ We have confined our attention to a positive analysis of status quo bias. While the reforms that we consider are efficiency-enhancing, they are not Paretoefficient, given the assumed absence of lump-sum transfers.
}

in general, there exist $c_{i}$ such that

$$
v\left(P^{*}, w_{x}^{*}-\theta-c_{i}\right)>v\left(P^{0}, w_{y}^{0}\right)
$$

where $v(\cdot)$ is the individual's indirect utility function. ${ }^{12}$

In order to provide a clear example, we further specify some characteristics of this economy: we assume that individuals' preferences are identical, risk-neutral, and given by

$$
V(P, I)=v(P) I=\frac{I}{P^{\gamma}}
$$

where $I$ is the individual's income level and $1 \geq \gamma>0$. The function $f(c)$ is assumed to be distributed uniformly on the interval $[0, \bar{c}]$, so $f(c)=1 / \bar{c}$, and thus, $\tilde{c}=(2 \theta \bar{c})^{0.5}$.

Note first that $w_{x}^{*}=P^{*} / a_{x}=w_{y}^{*}+\tilde{c}=$ $w_{y}^{0}+\tilde{c}=\left(1 / a_{y}\right)+\tilde{c}$ and, therefore, $P^{*}=$ $P^{0}+\tilde{c} a_{x}$. Thus, we must show that there exist $c_{i}$ such that

$$
v\left(P^{*}\right)\left[w_{y}^{0}+\tilde{c}-\theta-c_{i}\right]>v\left(P^{0}\right) w_{y}^{0} .
$$

That is, we must show

$$
\left(P^{*}\right)^{-\gamma}\left[w_{y}^{0}+\tilde{c}-\theta-c_{i}\right]>\left(P^{0}\right)^{-\gamma} w_{y}^{0} .
$$

Noting that $P^{*} / P^{0}$ can be written as $1+\tilde{c} a_{y}$ yields

$$
\begin{aligned}
1 / a_{y} & +(2 \theta \bar{c})^{-0.5}-\theta-c_{i} \\
> & \left(1 / a_{y}\right)\left[1+a_{y}(2 \theta \bar{c})^{-0.5}\right]^{\gamma}
\end{aligned}
$$

which can be satisfied for many parameter values (e.g., $\left.a_{y}=\theta=1, \bar{c}=2, \gamma=0.5\right){ }^{13}$

\footnotetext{
${ }^{12}$ Throughout this discussion, in order to further simplify exposition, we assume that tariff revenue is distributed solely among those workers originally located in sector $x$.

${ }^{13}$ Note that if $\gamma=1$ (i.e., individuals only consume good $X$ ), then the above inequality can never be satisfied, since the wage increase in sector $x$ would leave individuals with the same real wage as prior to the reform, and moreover, the individual would have paid the general and individual-specific investment cost.
} 


\section{Dynamic Considerations}

The model discussed above establishes that certain reforms that would have been popular ex post may not muster support ex ante. So far, it does not establish a bias toward protection, however. As mentioned in Section I, it is possible to come up with instances in which reform is embraced initially, only to prove unpopular once the identities of winners and losers are revealed. In a static setting, the logic of uncertainty works symmetrically, making both cases "equally" likely.

There is good reason to suspect, however, that in practice there will exist an asymmetry in favor of the status quo (protection). The asymmetry arises from the fact that new information is revealed in the case in which a reform is initially embraced and instituted, while no such thing happens when the reform is rejected from the outset. Therefore, if given a second chance, the electorate may reverse a reform that has been "mistakenly" embraced. Moreover, when considering a set of reforms that may possess a short life span due to the fact that it will be overturned in the future, rational forward-looking individuals may vote against reforms that initially appear to benefit them. By contrast, if an electorate initially chooses to reject a reform, the electorate will not change its vote. Since no new information is revealed in the latter case, an electorate that has refused reform once will continue to do so no matter how many times it is given an opportunity to reconsider. ${ }^{14}$ Thus, there is an important asymmetry between the time consistency of the status quo and the time consistency of certain reforms.

We will now show (i) that reforms, even if instituted with majority support, may be short-lived and (ii) that there is a tendency toward inertia (toward the maintenance of the status quo) in these economies. To introduce dynamic considerations into the framework, we turn to a two-period version of the model. Individuals are able to vote at

\footnotetext{
${ }^{14}$ This statement is subject to a caveat, as will be made clear in the exposition of the argument.
}

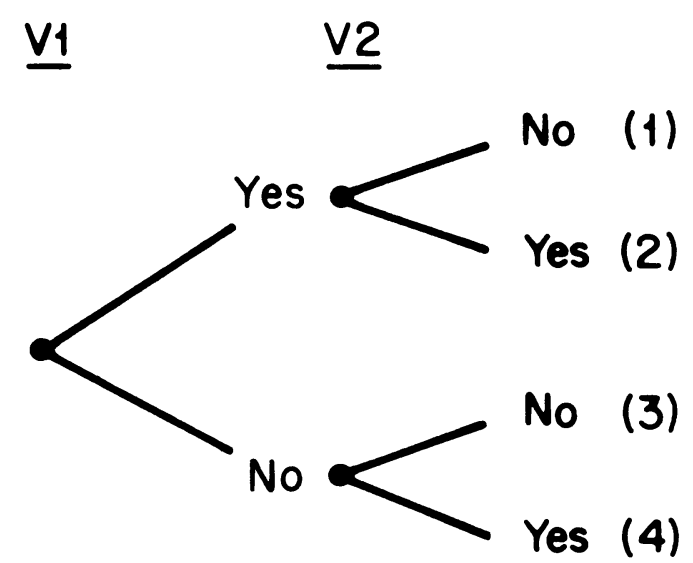

Figure 3. Possible Outcomes When Individuals Vote in Each of Two Periods

the beginning of each period on whether to institute (or continue with) the reform during that period. A decision not to continue with a reform that was previously instituted is taken to imply a return to the original relative prices. In each period, after voting, individuals decide whether or not to incur the investment cost $\theta$ (paid up front in its entirety) and, as before, whether or not to switch sectors and incur the individualspecific cost. They then earn the corresponding wage in that period. The possible outcomes are exhibited in Figure 3.

There are four possibilities: (i) reform is first instituted and then reversed because it proves unpopular; (ii) reform is instituted and sustained because it proves popular; (iii) reform is always opposed; and (iv) reform is first rejected and then accepted. While (i)-(iii) are possible equilibrium outcomes, (iv) is not if, in this two-period model, the second period is not lengthier than the, first.

The problem posed by the existence of a period significantly lengthier than any other is that the possibility of strategic voting is introduced. In our two-period example this would entail all individuals voting against the reform in the first period and in favor of the reform in the second since, foreseeing that once uncertainty is resolved a majority will overturn the reform [case (i)], individuals prefer to reject the reform in the first 
round in order to institute it in the second round, thereby preserving the reform for a greater length of time. In the more plausible case of periods of equal length, strategic voting of this sort will never occur. Case (iv) will never be an equilibrium, since if voters reject the reform no information is revealed and, consequently, there is no incentive to accept the reform the following period. Since the existence of periods of uneven length is rather artificial, we henceforth rule it out, eliminating (iv) as a possible equilibrium outcome. Apart from this restriction, nothing qualitative in our results depends on the number of time periods or on the finiteness of individuals' horizons. Note, therefore, the bias toward the status quo: reforms that are initially rejected continue to be so, whereas some reforms that were previously accepted cannot be sustained.

To make the preceding discussion a bit more concrete, consider the same example as in the previous section, with identical parameters and with the same set of initial conditions. Suppose that the effect of the reform under consideration is to change relative prices from $P^{0}$ to $P^{\prime}>P^{*}>P^{0}$. $P^{\prime}$ is such that sector-y (and, of course, then also sector- $x$ ) individuals would be willing to vote in favor of this reform if they thought that, once instituted, the reform would be permanent. Thus, $P^{\prime}$ must satisfy

$$
\begin{array}{r}
v\left(P^{\prime}\right)\left\{\left[w_{x}^{\prime}(1+\delta)-\theta\right] F(\tilde{c})\right. \\
\left.-\int_{0}^{\tilde{c}} c f(c) d c+\left[w_{y}^{\prime}(1+\delta)-\theta\right][1-F(\tilde{c})]\right\} \\
>v\left(P^{0}\right) w_{y}^{0}(1+\delta)
\end{array}
$$

where $w_{j}^{\prime}$ is the equilibrium wage in sector $j$ associated with $P^{\prime}$. The terms in the braces constitute the expected income from the reform for an individual initially in sector $y$, and the expression on the right-hand side of the inequality is a sector-y individual's status quo utility. Note that the wage earnings of an individual are now multiplied by $1+\delta$, which is the appropriate discounting of wages earned over two periods $(0<\delta<1$ is the individual's discount factor). ${ }^{15}$ Letting $P^{\prime}$ be such that $\tilde{c}<\bar{c}$, expression (5) can be rewritten as

$$
\begin{aligned}
& v\left(P^{\prime}\right)[\tilde{c}(1+\delta) F(\tilde{c}) \\
&\left.-\int_{0}^{\tilde{c}} c f(c) d c+w_{y}^{\prime}(1+\delta)-\theta\right] \\
&>v\left(P^{0}\right) w_{y}^{0}(1+\delta)
\end{aligned}
$$

and $\tilde{c}$ can be expressed as

$$
\tilde{c}=\frac{a_{y} P^{\prime}-a_{x}}{a_{y} a_{x}} .
$$

Recalling that $w_{y}^{\prime}=w_{y}^{0}=a_{y}^{-1}$ and performing the appropriate substitutions yields

$$
\begin{gathered}
\left(\frac{(0.5+\delta)\left[a_{y} P^{\prime}-a_{x}\right]^{2}}{\left[a_{y} a_{x}\right]^{2} \bar{c}}-\theta\right) a_{y}(1+\delta)^{-1}+1 \\
>\left(\frac{P^{\prime}}{P^{0}}\right)^{\gamma}
\end{gathered}
$$

The above condition ensures that all $y$-sector individuals would vote in favor of a permanent trade reform that changes relative prices from $P^{0}$ to $P^{\prime}$, since their ex ante expected utility from this reform is greater than the level of utility enjoyed under the status quo. If, however, $F(\tilde{c}) L_{y}^{0}+$ $L_{x}^{0}<[1-F(\tilde{c})] L_{y}^{0}$, then, since the individuals who have remained in sector $y$ now enjoy a lower real wage than before, in the second period the majority of the population will vote against the reform and in favor of a return to the status quo. ${ }^{16}$

It should be noted that, although it may appear that reform would always be sup-

\footnotetext{
${ }^{15}$ As expressed in (5), $c_{l}$ is only incurred in the first period. We could have considered $c_{i}$ to be incurred in each period without altering any of our conclusions.

${ }^{16} \mathrm{~A}$ necessary condition for this phenomenon to occur is $\tilde{c}<\bar{c} / 2$.
} 
ported for a sufficiently large $P$, this is misleading. The size of the reform is constrained by the initial level of trade restrictions.

Will individuals still vote for the reform in period 1 , knowing that there will be a return to the status quo following the second vote? Forward-looking individuals will realize that the first-period vote now presents a choice between the status quo and temporary reform. They will vote for the latter only if

$$
\begin{array}{r}
v\left(P^{\prime}\right)\left[w_{x}^{\prime} F(\tilde{c})-\int_{0}^{\tilde{c}} c f(c) d c\right. \\
\left.+w_{y}^{\prime}[1-F(\tilde{c})]-\theta\right] \\
>v\left(P^{0}\right) w_{y}^{0} .
\end{array}
$$

Notice that second-period wages are equal across sectors (given a return to the status quo). ${ }^{17}$ Therefore, $y$-sector workers will vote for reform only if the expected first-period benefits exceed the costs. Since this condition is more restrictive than that of equation (5), as the differential between $w_{x}$ and $w_{y}$ now accrues for one period only, there will be cases in which a reform will be rejected even though it would have been embraced had it been perceived as permanent. Individuals will sometimes find it unprofitable to incur the investment costs for a transitory reform and, hence, will vote against the reform from the outset. However, the lower is $\delta$ (i.e., the more the future is discounted or the greater the interval between votes), the more likely it is that a reform that is accepted when permanent will still be accepted when temporary.

\section{Concluding Remarks}

Our framework has a number of interesting features. First, it shows how uncertainty regarding the identities of gainers and losers

\footnotetext{
${ }^{17}$ This allows us to bypass the question of whether sector- $x$ individuals who have relocated in sector $y$ must incur any costs if they wish to return to sector $x$.
}

can prevent an efficiency-enhancing reform from being adopted, even in cases in which reform would prove quite popular after the fact. As the extended version of the model shows, there is a bias towards the status quo. Second, the model suggests that an appropriately large reform will be needed to get individuals to respond in the desired manner. ${ }^{18}$ This is a conclusion shared with some other positive models of reform in which either hysteresis or asymmetric information plays a role (see Rodrik, 1989a,b). Third, our model helps explain an apparent puzzle: in countries like Korea, Chile, and Turkey, radical trade reforms introduced by autocratic regimes have not collapsed (and indeed have turned out to be popular), even though they had little support prior to reform. Our framework makes clear why ex ante hostility to reform and ex post support are quite consistent with each other.

It should be clear that our argument does not rest on the assumption of a democratic voting mechanism. One could also, for example, obtain the same qualitative results if decisions were made according to the preferences of a median interest group. What is crucial to our results is that there be no mechanism that costlessly translates the intensity with which individuals favor a proposed reform into outcomes (e.g., frictionless lobbying). Such a mechanism would, of course, implement all reforms that increase efficiency.

The question may arise as to whether feasible transfer schemes exist to institute otherwise unpopular trade reforms by popular support. In most models, the answer would be trivially "yes." Here, there is an important consideration that constrains the use of such "bribing" mechanisms. Any such transfer scheme may be time-inconsistent, providing incentives to the ex post majority to renege on the agreement. Of course, such questions can be settled only by examining the equilibria of particular "bribing" games.

\footnotetext{
${ }^{18}$ However, this is no longer true if individuals are risk-averse; a large reform would magnify the uncertainty and could solidify the preference for the status quo on account of the greater risk.
} 
It should also be obvious that, while we have selected trade reform as an example, the logic applies to any reform that creates a distribution of gains and losses whose incidence is partially uncertain. Since this is a characteristic of any important policy change one can think of-whether it be macroeconomic stabilization in developing countries, welfare reform in advanced industrial countries, or transition to a market economy in socialist countries-the general principle established here with respect to the obstinacy of the status quo has wide relevance.

An interesting extension which we do not explore in this paper would be to endogenize the set of reforms that are politically feasible and to allow individuals to choose not only between a specific reform and the status quo, but also among alternative reforms. A model with greater institutional structure would be needed to determine how these reforms are initially selected.

\section{REFERENCES}

Baldwin, Robert E., The Political Economy of U.S. Import Policy, Cambridge, MA: MIT Press, 1985.

Bhagwati, Jagdish, "Need for Reforms in Underdeveloped Countries" (Comment on Gunnar Myrdal), in Sven Grassman and Erik Lundberg, eds., The World Economic Order: Past and Prospects, New York: St. Martin's Press, 1981, pp. 526-33.

, Protectionism, Cambridge, MA: MIT Press, 1988.

Fernandez, Raquel and Rodrik, Dani, "Why Is Trade Reform So Unpopular? On Status Quo Bias in Policy Reforms," NBER
(Cambridge, MA) Working Paper No. 3269, 1990.

Krueger, Anne O., "Asymmetries in Policy Between Exportables and Import-Competing Goods," NBER (Cambridge, MA) Working Paper No. 2904, March 1989.

Krugman, Paul, "Is Free Trade Passé?" Journal of Economic Perspectives, Fall 1987, 1, 131-44.

Kuran, Timur, "The Tenacious Past: Theories of Personal and Collective Conservatism," Journal of Economic Behavior and Organization, September 1988, 10 , 143-71.

Mayer, Wolfgang, "Endogenous Tariff Formation," American Economic Review, December 1984, 74, 970-85.

and Riezman, Raymond, "Endogenous Choice of Trade Policy Instruments," Journal of International Economics, November 1987, 23, 377-81.

Rodrik, Dani, "Tariffs, Subsidies, and Welfare with Endogenous Policy," Journal of International Economics, November 1986, $21,285-99$.

, (1989a) "Promises, Promises: Credible Policy Reform via Signalling," Economic Journal, September 1989, 99, 75672.

(1989b) "Policy Uncertainty and Private Investment in Developing Countries," NBER (Cambridge, MA) Working Paper No. 2999, June 1989; Journal of Development Economics, forthcoming.

Samuelson, William and Zeckhauser, Richard, "Status Quo Bias in Decision Making," Journal of Risk and Uncertainty, March 1988, 1, 7-59.

Schelling, Thomas C., Choice and Consequence, Cambridge, MA: Harvard University Press, 1984. 